\title{
Performance analysis of Malaysian low voltage distribution network under different solar variability days
}

\author{
Nur Izzati Zolkifri, Chin Kim Gan, Meysam Shamsiri \\ CeRIA Faculty of Electrical Engineering, Universiti Teknikal Malaysia Melaka, Malaysia
}

\begin{tabular}{l} 
Article Info \\
\hline Article history: \\
Received Oct 8, 2018 \\
Revised Dec 6, 2018 \\
Accepted Dec 19, 2018 \\
\hline
\end{tabular}

\section{Keywords:}

Distribution network

Network losses

Solar variability

Voltage unbalance

\begin{abstract}
The widespread of Photovoltaic (PV) systems as one of the distributed generation technologies could have profound impact on the distribution networks operation, particularly on network losses and network voltages fluctuations. This is mainly caused by the high PV penetrations coupled with high solar variability in the countries with large cloud cover. Therefore, this paper presents an investigation on the impact of residential gridconnected PV system by utilizing a typical low voltage (LV) network in Malaysia under various solar variability days. In this study, there are three scenarios; where, each scenario were performed with different levels of PV penetration and five different solar variability days. The impacts of PV system allocation in different scenarios and various solar variability days are assessed in term of voltage unbalance and network losses. The results propose that Scenario 1: randomly allocation of PV systems across the LV network has the lowest voltage unbalance and network losses especially during overcast day.
\end{abstract}

Copyright () 2019 Institute of Advanced Engineering and Science. All rights reserved.

\section{Corresponding Author:}

Nur Izzati Zolkifri,

Faculty of Electrical Engineering, Universiti Teknikal Malaysia Melaka,

Hang Tuah Jaya, 76100 Durian Tunggal, Melaka, Malaysia.

Email: zatizolkifri@gmail.com

\section{INTRODUCTION}

Photovoltaic (PV) systems are the most widespread distributes generation (DG) in Malaysian low voltage (LV) distribution networks [1], [2]. Moreover, many high income nation such as U.S, Germany and Japan are committed tackling issue in improving the application of renewable energy. Encouragement form Sustainable Energy Development Authority (SEDA) Malaysia made many Malaysian have their own PV systems due to a lot of advantages in economic and technical aspects [3], [4]. However, Malaysia is placed in the equatorial region with experiencing tropical climate [5], [6]. The main advantage tropical climate is they receive large amounts of sunshine all over the year yet can reduce the greenhouse emission, global warming and increase independent energy by utilize solar energy [7]. Eventhough tropical climate luxurious with solar irradiance, the clouds in that area and sun's daily movement significantly affect the energy generation of PV systems [8], [9]. Therefore, energy produced by PV system are intermittent and fluctuates [10]. This proves that the energy generated from PV systems is depending to the irradiance and its distribution [11], [12]. The intermittent and stochastic supplied from PV generation can affect technical and economic for consumers such as reverse power flow, and fluctuation voltage [13], [14]. Reverse power flow can be occurred if the PV generation is greater than the local power demand which causing voltage rise [15], [16]. Otherwise, fluctuation voltage or voltage drops can be occurred if the power demand profile and PV generation are negatively correlated [17].

Study in [18] have done investigation of impact solar variability in Malaysian network by utilizing only $100 \%$ PV penetration level for all cases. In this regard, a detailed investigation on various PV variability 
and different level of PV penetration particularly at Malaysian LV residential networks are required. Thus, the performance of integration of PV system in various PV variability and different level of PV penetration was studied in this paper in terms of voltage unbalance and network losses. A typical LV network at Taman Impian Putra in Port Dickson, Malaysia was utilized as a reference network. There are three different scenario which are; Scenario 1: The PV system is randomly allocated among feeder A, B and C, Scenario 2: PV systems are allocated randomly only at feeder A and feeder B, and Scenario 3: PV systems are allocated in an unbalanced manner. All the scenarios are tested with five different PV variability in order to determine which solar variability give high impact in network losses and voltage unbalance and to determine which level of penetration level create high network losses and voltage unbalance.

\section{RESEARCH METHOD}

\subsection{Low Voltage Network Modelling}

Taman Impian Putra located in Port Dickson, Malaysia was utilized as reference LV network for this paper. The detailing of this network was obtained from TNB as well as site visits. This LV network is a typical LV residential network in Malaysia. The network is modelled in the Open Distribution System Simulator (OpenDSS) which also act as the simulation tool to perform the power flow calculations [19]. The available data obtained from TNB and site visits are the transformer rating, number of feeders, cable types and the cable rating. By following utility's distribution planner handbook the feeder's loading of this network are not exceed than 50\% of the feeder's rated capacity [20]. In modelling this LV network, the neutral wire, mutual impedance and self-impedance of the cables are considered.

Based on the Figure 1, the LV network consists of three main feeders named Feeder A, Feeder B and Feeder $\mathrm{C}$ which consists of 52 houses, 64 houses and 33 houses, respectively. The houses across the feeders was categorized into two types which are terrace house and single storey house with $3 \mathrm{~kW}$ and $1.5 \mathrm{~kW}$ of diversity maximum demand, respectively [21]. In addition, all the feeders was linked to the $11 \mathrm{kV} / 0.4 \mathrm{kV}$ distribution transformer. The detailing of cable from one point to another point was described in the Table 1.

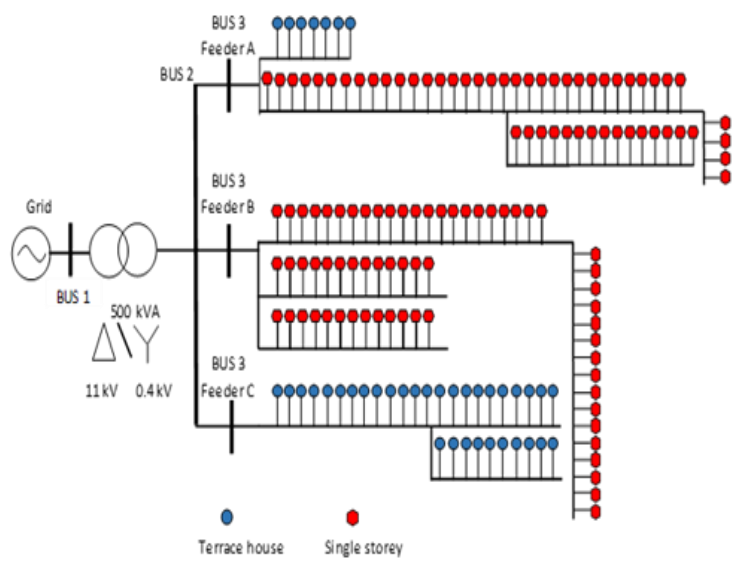

Table 1. Detailing size and Types of Cable

\begin{tabular}{ccc}
\hline \multicolumn{2}{c}{ Branch section } & Type of Cable \\
\hline From & To & $4 \times 500 \mathrm{~mm}^{2} \mathrm{PVC} / \mathrm{PVC}$ \\
transformer & Bus 2 & AL. \\
& Piecing & $185 \mathrm{~mm}^{2} \mathrm{PVC} / \mathrm{PVC} \mathrm{AL}$ \\
Bus 2 & connection & \\
& A,B,C & Aerial Bundle Cable \\
Piecing & Node & $(\mathrm{ABC}) 3 \times 185 \mathrm{~mm}^{2}+$ \\
connection & & $120 \mathrm{~mm}^{2} \mathrm{AL}$ \\
A,B,C & House & $16 \mathrm{~mm}^{2} \mathrm{PVC} / \mathrm{PVC} \mathrm{Cu}$. \\
Node &
\end{tabular}

Figure 1. Reference LV network located at taman impian putra

\subsection{Consumer Demand Modelling and Solar Variability}

Figure 2 shows the typical Malaysia's residential demand profile recorded at the distribution substation. Figure3 to Figure7, shows five different solar variability on clear day, overcast day, moderate variability, mild variability and high variability, respectively. The measured Global Horizontal Irradiance (GHI) values of five different PV variability utilized in this paper are collected from a weather station located on the rooftop of the Faculty of Electrical Engineering, Universiti Teknikal Malaysia Melaka $\left(2.32^{\circ} \mathrm{N}\right.$, $102.3^{\circ} \mathrm{E}$ ) [5]. The performance of LV network in this paper is evaluated based on these five solar variability. 


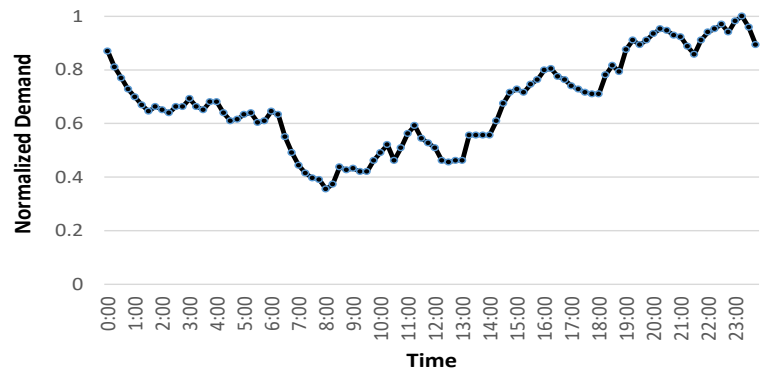

Figure 2. Typical Malaysia’s residential demand profiles

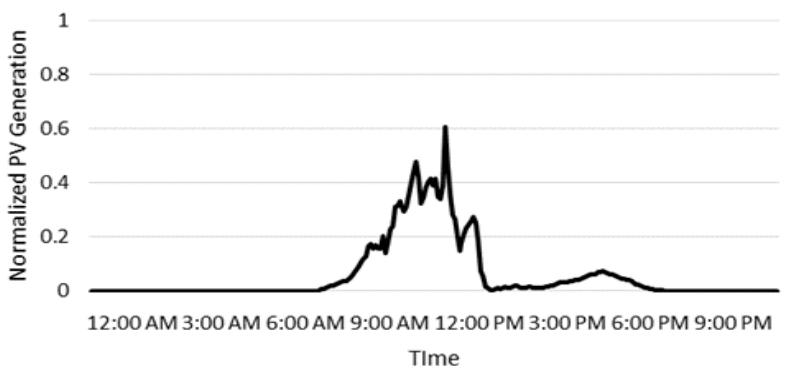

Figure 4. Sample of overcast day

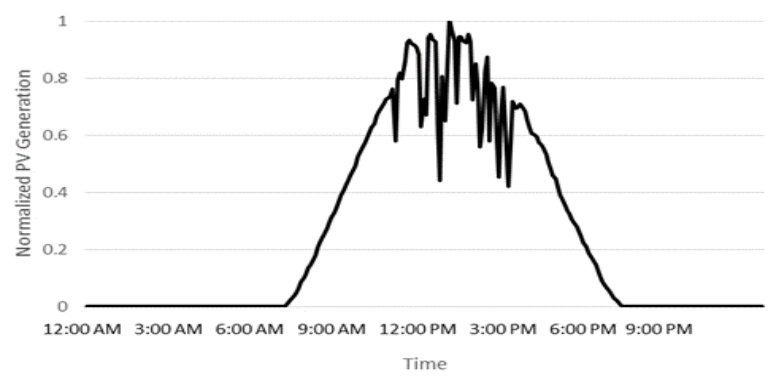

Figure 6. Sample of Mild variability day

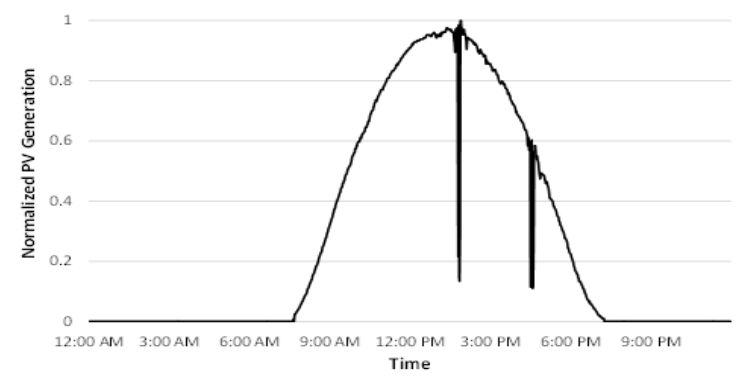

Figure 3. Sample of clear day

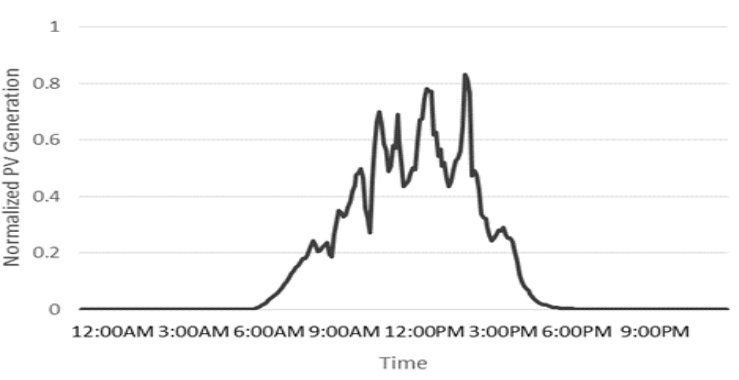

Figure 5. Sample of moderate variability day

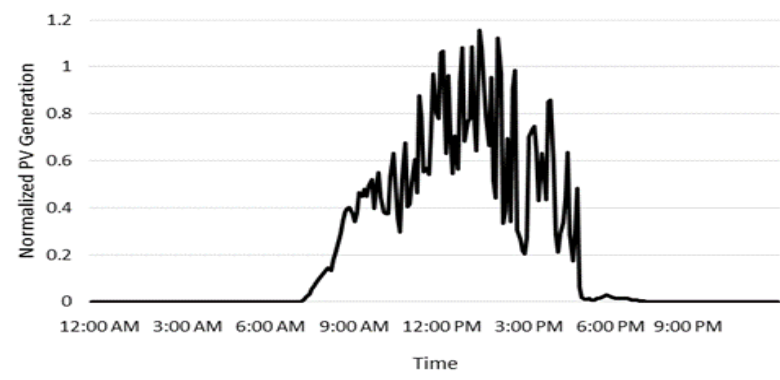

Figure 7. Sample of high variability day

\subsection{Voltage Unbalance}

Voltage unbalance occurs due to the unplanned connection of PV system to the distribution network [22]. The allocation of PV system across the feeder is one of the main factor of voltage unbalance. In Malaysia, Tenaga Nasional Berhad (TNB) as one of electricity utility, has set $1.0 \%$ as the statutory limit of the network voltage in Malaysia which is stricter compared to UK (1.3\%) and EU (2\%) [23]. As shown is 1 depicts the percentage equation of Line Voltage Unbalanced Rate (LVUR) [22].

$$
\% L V U R=\frac{\text { Max voltage deviation from average } V_{L}}{\text { average } V_{L}} * 100 \%
$$

Where $\mathrm{V}_{\mathrm{L}}$ is line voltage.

\subsection{Network Losses}

Production of power losses are mainly from the cable resistance and it can be reduced through integration of PV system. Study in [24] has shown that mild PV penetration sufficient the local demand and network losses will drop to its minimum. Otherwise, high PV penetration can bring out reverse power flow situation in the network thus increase the network losses. As shown is 2 shows mathematical equation of network losses. 


$$
\% \text { losses }=\frac{\text { Network energy losses }}{\text { Energy Consumption of base case }} * 100 \%
$$

\subsection{Case Study}

In the previous study, the impacts of residential solar PV systems on network voltage unbalance and network losses was investigated [25]. The paper utilized a typical clear day PV generation profiles only. However, in this paper same investigation was run with five different PV variability which are clear day, overcast day, moderate variability, mild variability and high variability day as in Figure 3 to Figure 7 respectively. Same as the previous paper [25], this paper consists of three scenario which are; random PV allocation, random concentrated PV allocation and unbalanced PV system installation. The PV penetration level in this study was varied from $0 \%$ to $100 \%$. This paper applied penetration by number of houses as the $\mathrm{PV}$ penetration level and been defined as in as shown is 3. The total houses connected across the feeder are 149 houses. More details, load connected across the three feeders are $88.5 \mathrm{~kW}$ (feeder A), 96kW (feeder B) and $99 \mathrm{~kW}$ (feeder C). Furthermore, the size of PV capacity installed to the houses are according to SEDA's database in kilowatt peak $(\mathrm{kWp})$ capacity. The percentage of $3 \mathrm{kWp}, 4 \mathrm{kWp}$ and $5 \mathrm{kWp}$ PV system connected to LV network are $3 \%, 80.74 \%$, and $16 \%$, respectively. All the three scenarios utilized the same percentage of PV capacity.

$$
\% P V \text { penetration level }=\frac{\text { house with } P V \text { system }}{\text { total house at feeders }} * 100 \%
$$

\subsubsection{Scenario 1: PV System Randomly Allocated Across Feeder A, B and C}

Scenario 1 is where the PV systems with various capacities as mentioned above were randomly installed across the three feeders. It should be noted that the normal distribution function is used in this paper for random allocating the PV system among the houses. The PV penetration level installed in this scenario is starting from $10 \%$ to $100 \%$. In order to record the power flow and voltage profiles, a meter was installed at the end of the feeders. Table 2 shows the number of load installed randomly according to percentage of PV penetration level. Same condition is repeated for five different PV variability which are clear day, overcast day, moderate variability, mild variability and high variability day.

Table 2. Number of Houses According to PV Penetration Level

\begin{tabular}{cc}
\hline PV penetration level & No. of houses connected to PV system for Scenario 1 \\
\hline $0 \%$ & 0 \\
$10 \%$ & 15 \\
$25 \%$ & 37 \\
$50 \%$ & 75 \\
$75 \%$ & 112 \\
$100 \%$ & 149 \\
\hline
\end{tabular}

\subsubsection{Scenario 2: PV System Randomly Allocated and Concentrated Across Feeder A and B Only}

The main purpose of second scenario is to determine the potential issue of randomly allocate the PV system concentrated on two feeders which are feeder A and B. The PV penetration level for this scenario is varied starting from $10 \%$ to $75 \%$. The $100 \%$ of PV penetration worth nothing since it's in balanced connection and the result obtained will same as scenario 1 . Table 3 shows the number of houses concentrated at feeder A and B according to PV penetration level. This process is start with $10 \%$ penetration level installed across the feeder A and it is persist until each houses in feeder A own one PV system. The next PV penetration level will be installed across the feeder B, until up to $75 \%$ penetration level. Same condition is repeated for five different PV variability which are clear day, overcast day, moderate variability, mild variability and high variability day.

Table 3. Number of Houses Concentrated at Feeder A and B According to PV Penetration Level

\begin{tabular}{cccc}
\hline \multirow{2}{*}{ PV penetration level } & \multicolumn{3}{c}{ No. of houses connected to PV system } \\
& Feeder A & Feeder B & Feeder C \\
\hline $0 \%$ & 0 & 0 & 0 \\
$10 \%$ & 15 & 0 & 0 \\
$25 \%$ & 37 & 0 & 0 \\
$50 \%$ & 52 & 23 & 0 \\
$75 \%$ & 52 & 60 & 0 \\
\hline
\end{tabular}




\subsubsection{Scenario 3: Unbalanced Allocation of PV System}

Scenario 3 can be classified as an extreme condition because the PV system is placed in the most unbalanced manner. Firstly, the PV system is connected at the first phase (Phase 1) of all the three feeders. After the 'Phase 1' at the three feeders was entirely installed, the process was proceed to the second phase (Phase 2). Then, after second phase (Phase 2) was fully connected with PV system, it will continue to the third phase (Phase 3). The procedure is began in sequence 10\% to 75\% penetration level. Table 4 shows how the above process flow. The process of Scenario 3 is repeated for five different PV variability which are clear day, overcast day, moderate variability, mild variability and high variability day.

Table 4. Number of Houses According to PV Penetration Level for Scenario 3

\begin{tabular}{|c|c|c|c|c|c|c|c|c|c|}
\hline \multirow{3}{*}{$\begin{array}{l}\text { PV penetration } \\
\text { level }\end{array}$} & \multicolumn{9}{|c|}{ No. of houses connected to PV system } \\
\hline & \multicolumn{3}{|c|}{ Feeder A } & \multicolumn{3}{|c|}{ Feeder B } & \multicolumn{3}{|c|}{ Feeder C } \\
\hline & $\mathrm{P} 1$ & $\mathrm{P} 2$ & P3 & P1 & $\mathrm{P} 2$ & P3 & P 1 & $\mathrm{P} 2$ & P 3 \\
\hline $0 \%$ & 0 & 0 & 0 & 0 & 0 & 0 & 0 & 0 & 0 \\
\hline $10 \%$ & 15 & 0 & 0 & 0 & 0 & 0 & 0 & 0 & 0 \\
\hline $25 \%$ & 18 & 0 & 0 & 19 & 0 & 0 & 0 & 0 & 0 \\
\hline $50 \%$ & 18 & 18 & 0 & 23 & 4 & 0 & 12 & 0 & 0 \\
\hline $75 \%$ & 18 & 18 & 9 & 23 & 21 & 0 & 12 & 11 & 0 \\
\hline
\end{tabular}

where: $\mathrm{P} 1=$ Phase 1; P2 = Phase 2; P3 = Phase 3

\section{RESULTS AND ANALYSIS}

\subsection{Scenario 1: PV System Randomly Allocated Across Feeder A, B and C}

The impact of five different PV profile of single phase PV integration on voltage unbalance was evaluated. Figure 8 (a), (b) and (c), shows the impact of voltage unbalance at the feeders with five different PV profiles. All the PV variability in Feeder A, B, and C shows maximum voltage unbalance during 25\% PV penetration level which lead by high variability, clear day, mild, moderate and lastly is overcast day. When the feeders reach their peak voltage unbalance, its start to fall until it reach $100 \%$ PV penetration. This is because the increasing of single phase PV connection will reduce the unbalance power supply in the three-phase network distribution. The voltage unbalance in every feeder is differ because it's depend on the feeder characteristic and the number of PV system randomly allocated across the feeder. Based on the result, all the PV variability exceed statutory limit (1\%) of voltage unbalance in Malaysia except overcast day due to low power generation by PV system. The highest voltage unbalance recorded in this scenario is high variability at feeder A with $1.9 \%$ which is over the statutory limit (1\%).

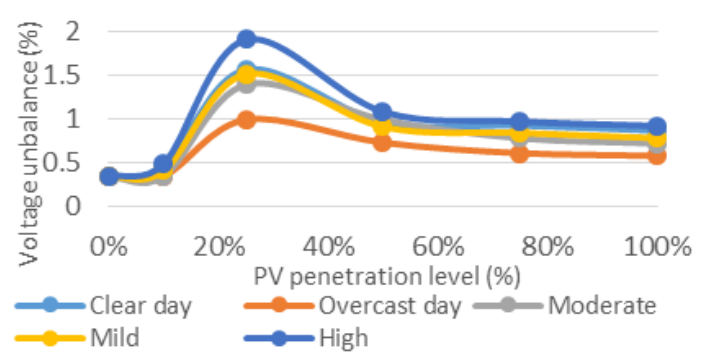

(a)

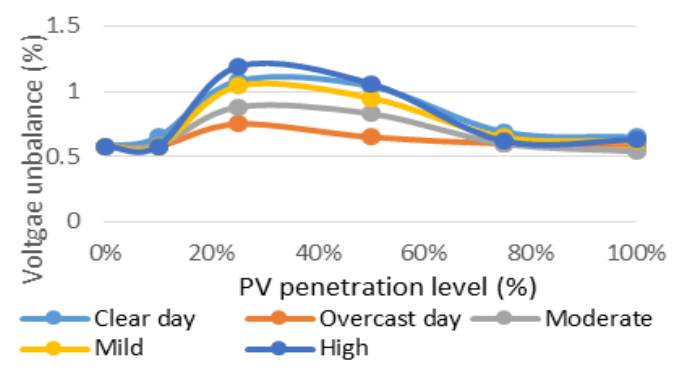

(c)

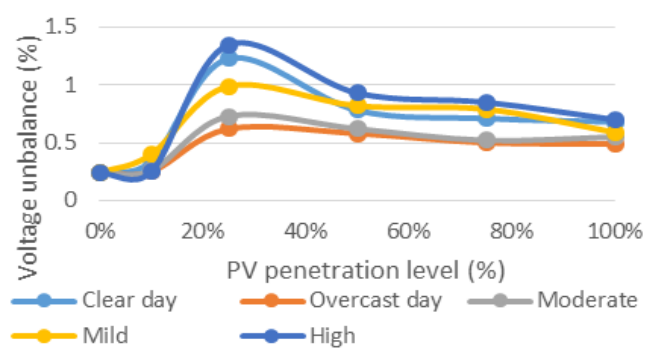

(b)

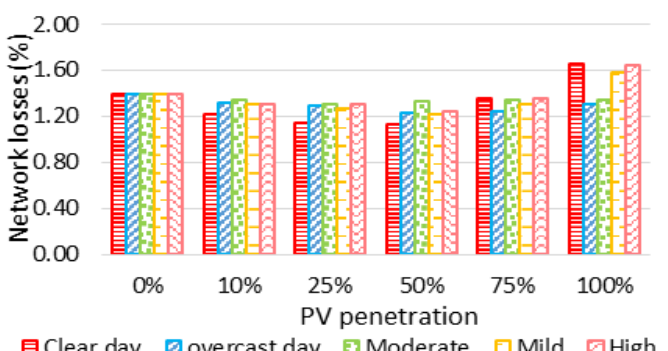

(d)

Figure 8. Voltage unbalance in feeder A (a) feeder B (b) and feeder C (c) and Network losses (d) for Scenario 1 
Figure 8 (d) shows the network losses from base case until fully installed PV system at the distribution network. The network losses result was recorded every five-minutes in OpenDSS software. Generally, all the five PV variability shows the same 'U-shape' pattern. Whereby, all the network losses start fall gradually from base case point until approximately 50\% PV penetration. This mainly causes by the PV generation capable in reducing the network losses. However, when PV penetration increase over 50\% penetration, the network losses slightly increased. This situation occur because of reverse power flow due to PV generation power exceeded the load consumption in the network. The significant reverse power flow can be seen during clear day, mild and high variability. This is because PV generation on these day is high compared to overcast day and moderate.

\subsection{Scenario 2: Concentrated Allocation PV system at Feeders A and Feeder B}

This section discusses the impact of concentrated allocation PV system with five different PV profile on voltage unbalance. Figure 9 (a) shows feeder A have highest percentage of voltage unbalance approximately $25 \%$ PV penetration and decrease after its reached maximum voltage unbalance. This is because after 25\% PV penetration, the three single-phase of the three-phase distribution network become 'balanced' due to the increasing number of PV connection. On the other hand, Figure 9 (b) shows voltage unbalance in feeder B reached at their maximum approximately $50 \% \mathrm{PV}$ penetration and after $50 \% \mathrm{PV}$ penetration, voltage unbalance fall gradually until 75\% PV penetration level. This is because the unbalance connection of three single phase PV system turn to balanced connection when the percentage of PV penetration increase. In addition, Figure 9 (c) shows feeder $C$ having a constant voltage unbalance result due to PV system was not connected across the feeder. In term of PV variability, high variability for both feeder A and B have highest voltage unbalance then followed by clear day, mild, moderate and overcast day. The result proven that the main factor voltage unbalance occur because of the allocation of PV system and percentage of PV penetration level itself. While, PV variability will specify the percentage level of voltage unbalance and it's depend on their PV generation output power.

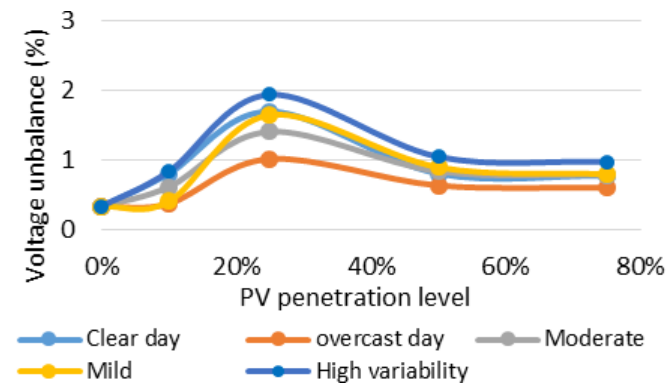

(a)

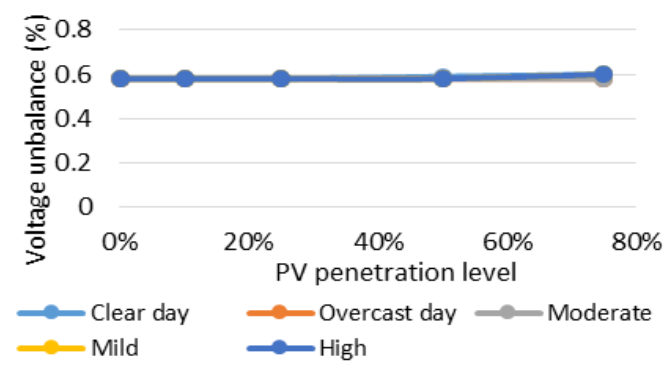

(c)

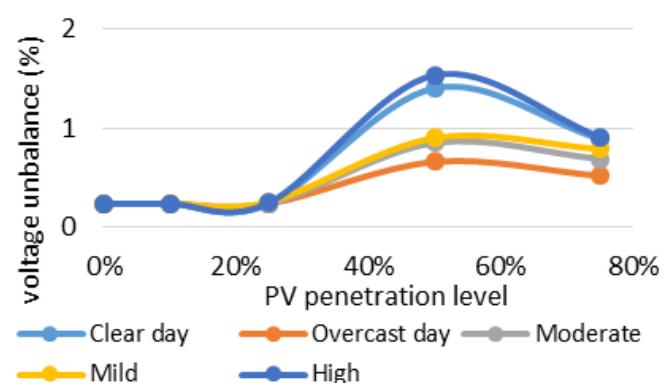

(b)

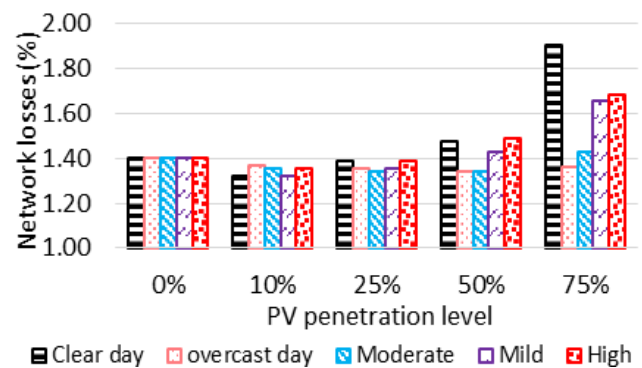

(d)

Figure 9. Voltage unbalance in feeder A (a), feeder B (b) and feeder C (c) and Network losses (d) for Scenario 2

The simulation result of network losses can be seen in Figure 9 (d) with five different PV penetration. This scenario does not showing a significant 'U-shape' pattern of network losses in each PV variability. The network losses trend for the first $25 \%$ penetration shows a slight reduction which is less than $0.10 \%$ for all days. Since PV system was not connected to feeder C, losses at feeder C remain unchanged. PV variability above $50 \%$ penetration produce high losses until $100 \%$ penetration due to PV generation exceed the load consumption which lead to the reverse power flow. Overcast day shows a fairly constant result from

Performance analysis of Malaysian low voltage distribution network under different... (Nur Izzati Zolkifri) 
base case to $100 \%$ penetration level due to low power generation and did not causes high network losses. While, clear day shows the highest network losses when it reach $100 \%$ penetration with $1.90 \%$ due to high generation supplied at low power demand and directly increased the network losses to the maximum.

\subsection{Scenario 3: Unbalanced Allocation of PV System}

Figure 10 (a), (b), and (c) show results of voltage unbalance for feeder A, feeder B and feeder $\mathrm{C}$ for Scenario 3. The impact of five different PV variability on voltage unbalance was assessed from $0 \%$ to $75 \%$ PV penetration level. The result shows a significant voltage unbalance especially during $50 \%$ PV penetration level. Same trend with the other scenarios, high variability has the highest voltage unbalance followed by clear day, mild, moderate and overcast day. This is because high variability is well known as a high power generation with high fluctuation PV output power which will resulted high voltage unbalance in the feeder. All the PV variability included overcast day have highest voltage unbalance until they reached $5 \%$ voltage unbalance. This scenario have proven that allocation PV system in unbalance way will contribute to high voltage unbalance in the feeder especially during high variability. This is a serious problem in the distribution network having high voltage unbalance because it will contribute to downturn performance and short life span of equipment like distribution transformer and household's sensitive equipment.

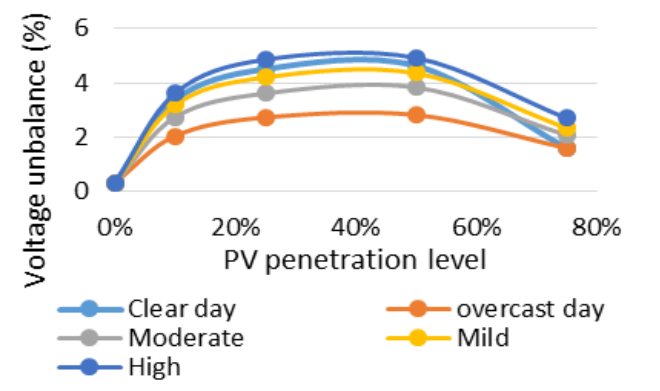

(a)

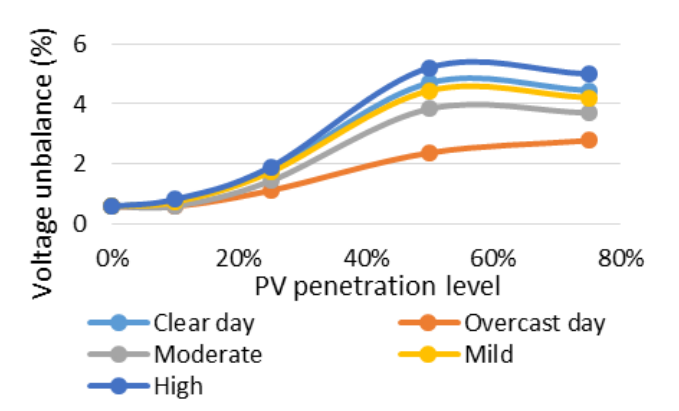

(c)

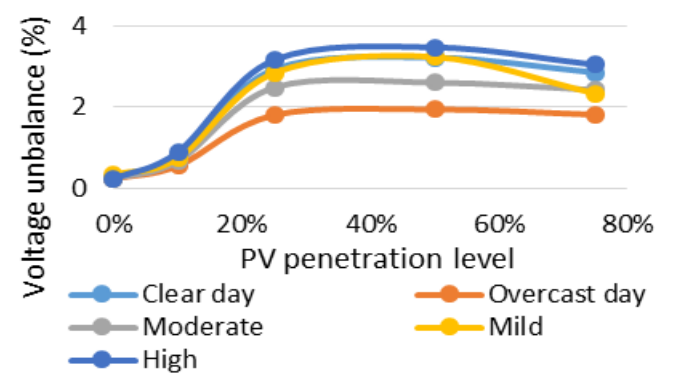

(b)

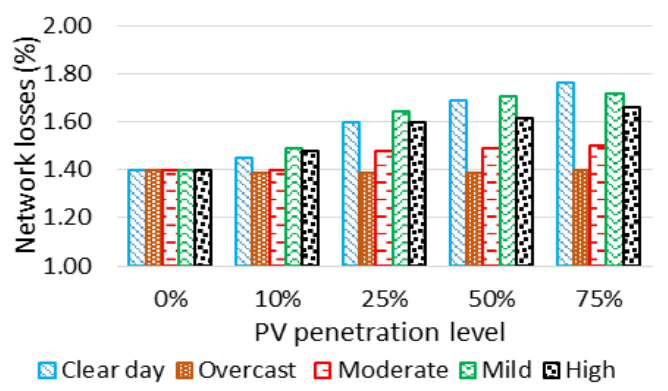

(d)

Figure 10. Voltage unbalance in feeder A (a), feeder B (b) and feeder C (c) and Network losses (d) for Scenario 3

Figure 10 (d) shows network losses for unbalance allocation PV system with five different PV variability. Generally, as can be seen in Figure 10 (d) network losses of the PV variability increase in linear manner. This is mainly due to effect of unbalance allocation of PV system across the feeders. Clear day, mild and high variability shows significant increment of network losses across every level of PV penetration. This is driven by reverse power flow due to high PV generation during that day. Overcast day and moderate variability have a fairly constant result due to low power generation and there is low probability of surplus power that lead to the reverse power flow at their high PV penetration.

\section{CONCLUSION}

This paper has presented the performance of five different PV variability in term of voltage unbalance and network losses in three different scenarios. The performance was evaluated from $0 \%$ to $100 \%$ PV penetration level. In term of PV variability, overcast day shows the lowest network losses and voltage 
unbalance especially during below than $50 \% \mathrm{PV}$ penetration. Otherwise, clear day and high variability has the highest voltage unbalance and network losses since they generate high supply to the network which can lead to reverse power flow. The study suggests that the normal distribution function in allocating the PV system along all the feeders' are well-suited way to set up PV system at residential area is. As expected from the results, the normal distribution of PV system concluded with less voltage unbalance and network losses particularly at moderate PV penetration level (not more than 50\%). Lastly, based on the study, unbalance allocation PV system at the feeder should be avoided because it recorded high voltage unbalance and network losses for each solar variability particularly during high variability.

\section{ACKNOWLEDGEMENTS}

The authors would like to thank and acknowledge the Ministry of Higher Education Malaysia and Universiti Teknikal Malaysia Melaka for supporting this research through RAGS/1/2015/TK03/FKE /03/B00096.

\section{REFERENCES}

[1] M. Ministry of Energy, "Green Technology and Water," Handbook on the Malaysian Feed-in-Tariff for the Promotion of Renewable Energy, 2011.

[2] The Economic Planning Unit, "10th Malaysia Plan (Chapter 6: Building and Environment that Enhances Quality of Life),” The Economic Planning Unit, Prime Minister's Department, 2010.

[3] KeTTHA, "Handbook on the Malaysian feed-in tariff for the Promotion of Renewable energy," pp. $28,2011$.

[4] S. Koohikamali, et al., "Impacts of Grid-Connected PV System on the Steady-State Operation of a Malaysian Grid," pp. 858-863, 2010.

[5] K. Azmi, et al., "Quantifying variability for grid-connected photovoltaics in the tropics for microgrid application," Energy Procedia, vol. 103, pp. 400-405, 2016.

[6] D. Burnett, et al., "The UK solar energy resource and the impact of climate change," Renewable Energy, vol. 71, pp. 333-343, 2014.

[7] W. A. Omran, et al., "Investigation of methods for reduction of power fluctuations generated from large gridconnected photovoltaic systems," IEEE Transactions on Energy Conversion, vol/issue: 26(1), pp. 318-327, 2011.

[8] L. L. Jiang, et al., "Power variability of small scale PV systems caused by shading from passing clouds in tropical region," IEEE 43rd Photovoltaic Specialists Conference (PVSC), Portland, OR, pp. 3159-3164, 2016.

[9] C. Y. Lau, et al., "Impact of Solar Photovoltaic System on Transformer Tap Changer in Low Voltage Distribution Networks," Energy Procedia, vol. 103, pp. 58-63, 2016.

[10] M. Ministry of Energy, "Green Technology and Water," Handbook on the Malaysian Feed-in-Tariff for the Promotion of Renewable Energy, 2011.

[11] K. Engeland, et al., "Space-time variability of climate variables and intermittent renewable electricity production A review," Renewable and Sustainable Energy Reviews, vol. 79, pp. 600-617, 2017.

[12] N. K. Kandasamy, et al., "Virtual storage capacity using demand response management to overcome intermittency of solar PV generation," IET Renew. Power Gener., vol/issue: 11(14), pp. 1741-1748, 2017.

[13] S. Shivashankar, et al., "Mitigating methods of power fluctuation of photovoltaic (PV) sources - A review," Renewable and Sustainable Energy Reviews, vol. 59, pp. 1170-1184, 2016.

[14] W. A. Omran, et al., "Investigation of methods for reduction of power fluctuations generated from large gridconnected photovoltaic systems," IEEE Transactions on Energy Conversion, vol/issue: 26(1), pp. 318-327, 2011.

[15] D. I. Doukas, et al., "On reverse power flow modelling in distribution grids," Mediterranean Conference on Power Generation, Transmission, Distribution and Energy Conversion (MedPower 2016), Belgrade, pp. 1-6, 2016.

[16] S. Ali, et al., "Impact of High Penetration Level of Grid-Connected Photovoltaic Systems on the UK Low Voltage Distribution Network," International Conference on Renewable Energies and Power Quality, pp. 2-5, 2012.

[17] F. Lamberti and G. Graditi, "Impact Analysis of Distributed PV and Energy Storage Systems in Unbalanced LV Networks,” 2015 IEEE Eindhoven PowerTech, Eindhoven, pp. 1-6, 2015.

[18] V. Annathurai, et al., "Impacts of Solar Variability on Distribution Networks Performance," vol/issue: 12(7), pp. 1151-1155, 2017.

[19] Simulation tool-OpenDSS, “Smart Grid Resources," Electrical Power Research Institute (EPRI), 2001-2011.

[20] TNB, "Distribution Planners Handbook," 2012.

[21] TNB, "Electricity Supply Application Handbook Supply," 2011.

[22] P. Pillay and M. Manyage, "Definitions of Voltage Unbalance," IEEE Power Engineering Review, pp. 50-51, 2001.

[23] K. H. Chua and J. Wong, "Mitigation of Voltage Unbalance in Low Voltage Distribution Network with High Level of Photovoltaic System," Energy Procedia, vol. 12, pp. 495-501, 2011.

[24] C. H. Tie and C. K. Gan, "Impact of Grid-Connected Residential PV Systems on the Malaysia Low Voltage Distribution Network," IEEE 7th International Power Engineering and Optimization Conference (PEOCO2013), Langkawi, Malaysia, pp. 670-675, 2013.

[25] N. I. Zolkifri, et al., "Impacts of residential solar photovoltaic systems on voltage unbalance and network losses," TENCON 2017 - 2017 IEEE Region 10 Conference, Penang, pp. 2150-2155, 2017. 


\section{BIOGRAPHIES OF AUTHORS}

\begin{tabular}{|l|l|} 
Nur Izzati Zolkifri obtained her B. Eng (Hons) in electrical engineering from Universiti Teknikal \\
Malaysia Melaka in 2016. She is currently pursuing her M.Sc degree in electrical engineering. \\
Her current research interests include distributed generation, integration of renewable energy, \\
impacts of PV system on distribution networks and energy storage.
\end{tabular}

